\title{
Prophylactic Mastectomy Patient
}

National Cancer Institute

\section{Source}

National Cancer Institute. Prophylactic Mastectomy Patient. NCI Thesaurus. Code C147117.

An individual who is undergoing prophylactic mastectomy. 